\title{
TEMPOS E CONTRATEMPOS DA EDUCAÇÃO DE SURDOS EM PORTUGAL EM CENÁRIOS DE EDUCAÇÃO BILINGUE ${ }^{*_{1}}$
}

\author{
Joaquim Melro
}

\section{Escola espelho meu...}

\begin{abstract}
A educação que se impõe aos que verdadeiramente se comprometem com a libertação não pode fundar-se numa compreensão dos homens como seres "vazios" a quem o mundo "encha" de conteúdos [...] , mas a da problematização dos homens em suas relações com o mundo (FREIRE, 1984 , p. 67, aspas no original).
\end{abstract}

Iniciamos este capítulo, evocando o pensamento do grande pedagogo brasileiro, Paulo Freire, homenageando-o e, como ele, todos os que à educação têm dedicado as suas vidas, lutando, em contextos nem sempre fáceis nem sempre lineares, para que ela se constitua um direito de facto de todos os seres humanos. Como sublinha Paulo Freire (1984), a essência da Educação deve ser entendida como praxis da liberdade, convidando homens e mulheres a (auto)problematizarem-se e a constituírem-se como (co)autores da (sua) história, que, mais não é, do que o convite ao exercício de cidadania e de participação legítima, dando corpo à sua vocação de SER MAIS. Educar é, como sublinha Freire $(1984,1999,2000)$, um compromisso da humanidade com humano. Um compromisso com uma ética que se quer do humano e para o humano. Um compromisso com a prazerosidade, com, enfim, a amorosidade, farol último de toda a praxis educativa: "A educação é um ato de amor, por isso, um ato de coragem. Não pode temer o debate. A análise da realidade.

\footnotetext{
*DOI - 10.29388/978-65-86678-60-4-0-f.175-204

${ }^{1}$ Este capítulo constitui-se numa revisão e aprofundamento da Comunicação apresentada pelo autor e por Margarida César ao XVI Colóquio da AFIRSE. Tutoria e mediação em educação: Novos desafios à investigação educacional, sob o título Educação inclusiva: Do ser ao agir e do dizer ao sentir, publicado em 2010 (Melro, 2010a) nas Actas deste Colóquio. Revisitando-a, damo-nos a oportunidade de sobre ele relançar um olhar mais maturado e mais contemporâneo, na certeza de podermos, de algum modo, contribuir para o debate, simultaneamente, diacrônico e sincrônico, das problemáticas que configuram a obra agora editada e da qual temos o prazer de participar.
} 
Não pode fugir à discussão criadora, sob pena de ser uma farsa", relembra Freire (1984, p.96).

Evocar Paulo Freire, permite-nos, também, afirmar que a Educação é um dos um dos pilares sobre os quais assenta a construção de sociedades mais democráticas, mais justas, mais equitativas e mais inclusivas - ideais retomados e/ou reforçadas por autores como Morin (2004) ou por Delors e seus colaboradores (2000).

A proclamação do direito de todos à educação, materializada, um pouco por todo o planeta, na universalização do acesso de todos à Escola, expressa a necessidade de as sociedades assumirem o compromisso éticopolítico de a todos garantir as condições necessárias ao exercício de uma cidadania ativa e participativa, ou como referem Lave e Wenger (1991), à participação legítima, arredando todas as formas de participação periférica, configuradas e configuradoras da discriminação, da segregação e da exclusão.

Contudo, garantir o acesso de todos à Escola, não significa necessariamente garantir a todos equidade no acesso ao sucesso escolar e social (ALLAN \& SLEE, 2008; CÉSAR, 2007, 2012; MELRO, 2014a, 2014b). Desgraçada e vergonhosamente, ontem como hoje, um pouco por todo o planeta, milhares de seres humanos continuam a não ver garantido o direito à educação. Milhares de seres humanos, continuam não só a não ter acesso à Educação, ou tendo-o, não garante, no entanto, que esse acesso seja sinónimo de poder usufruir de uma educação que satisfaça as respetivas necessidades educativas (CÉSAR \& AINSCOW, 2006; MELRO \& CÉSAR, 2009, 2012, 2013, 2014, 2017). Tal implicaria, o que nem sempre acontece, que os sistemas educativos consagrassem, nos princípios e nas práticas que apresentam formas de atuação que valorizassem a diversidade sociocultural que caracteriza as sociedades e a Escola (CÉSAR, 2007, 2013a, 2013b, MELRO \& CÉSAR, 2013, 2014, 2016).

No que a Portugal diz respeito, e apesar dos muitos avanços registados, dados recentes apontam para um cenário ainda marcado pela exclusão escolar, expressa em índices preocupantes de elevadas taxas de retenção e de abandono escolar, assim como de baixos níveis de literacia (INE, 2019; PORDATA, 2019), sendo essa exclusão mais agravada quando referida a estudantes que necessitam de apoios educativos e sociais especializado (AESE), 
como os surdos ${ }^{2}$, denotando urgir cumprir muitos dos compromissos assumidos em documentos de política educativa (ONU, 2007, UNESCO, 1994, 2015), dos quais Portugal é signatário.

Face a cenários educativos ainda configurados e configuradores de exclusão, César e Ainscow (2006), Allan e Slee (2008) ou César (2012), reforçam a necessidade de a Escola proceder a processos de mudança epistemológicos, educativos e socioculturais, de modo a que os ideais que iluminam a educação inclusiva, uma educação que satisfaça as necessidades educativas de todos os alunos, valorizando as suas características individuais e/ou sociais, sejam uma realidade possível. Os autores, não deixam contudo, de realçar que essa mudança tem vindo a ganhar cada vez maior relevância, sem que, contudo, seja ainda uma experiência possível em muitas das escolas, para quem a inevitabilidade da diversidade se constitui uma barreira difícil de transpor e onde a exclusão académica e social continua indelevelmente a imperar, como ilustram os resultados dos estudos que temos vindo a desenvolver sobre os modos como a Escola inclui os estudantes surdos (MELRO, 1999, 2003, 2014a), para quem o acesso a uma educação de qualidade ainda continua a ser uma miragem, porque a Escola se mostra incapaz de dar respostas adequadas às suas necessidades educativas e sociais (MELRO, 2014a, MELRO E CÉSAR, 2005, 2009, 2010a, 2016).

Consideramos os estudantes surdos como paradigma das dificuldades sentidas pela Escola em materializar os ideais da Educação Inclusiva. Participantes de uma cultura minoritária e falantes, na sua maioria, de uma língua materna pouco reconhecida e valorizada pelas escolas, a Língua Gestual Portuguesa (LGP), veem as suas aprendizagens comprometidas (MELRO, 2014a, MELRO, 2014b, 2015, 2017a), porque mediadas num processo de mediação ilusório, habitualmente em Língua Portuguesa (LP), que, dadas as características destes estudantes, não lhes têm acesso pleno. Ilusório porque, a Escola, numa espécie de teimosia monocultural e monolínguística, ao mediar hegemonicamente as interações sociais, bem como, as aprendizagens dos surdos através da LP, ilude quem ensina e quem aprende, esquecendo que a língua através da qual muitos surdos portugueses se estruturam e se

\footnotetext{
${ }^{2}$ Porque já apresentamos exemplos de outras culturas, como a cigana, e outros estudantes, como os cegos, que em Língua Portuguesa (LP) se designam com minúsculas, optamos por escrever surdos com minúscula, apesar de assumirmos um paradigma sócio-antropológico (MELRO, 2014a, 2014b). Dadas as características culturais da Língua Inglesa, optamos por escrever Deaf em maiúsculas, pelas razões sublinhadas.
} 
relacionam consigo mesmos e com os outros, o que inclui a construção das identidades e do conhecimento, é a LGP. Ilusório, porque incapaz de valorizar a diversidade linguístico-cultural dos surdos, insistindo em desenvolver um currículo monolíngue e hegemônico, não os faz sentirem-se capazes de construir o seu logos, como diriam Apel (1994) ou Vergnaud (2007), levando ao desespero de uns e de outros - de quem ensina e de quem aprende e vice versa (MELRO \& CÉSAR, 2010a, 2010b; MELRO, 2017a, 2017b).

Como realça Vygotsky (1989) a linguagem é mediadora entre a realidade e o ser humano. Ela constitui-se no meio através do qual este estrutura o seu pensamento, traduz o que sente e quer, comunica com os seus semelhantes, produz e constrói significação e sentido. Assim, a nossa posição no e sobre o mundo, ao qual pertencemos, depende, em grande parte, do modo pelo qual o mundo é estruturado pela e através da linguagem, assumindo esta um papel essencial na formação da consciência de si e do outro (APEL, 1995; VERGNAUD, 2007; VYGOTSKY, 1989). A Escola, enquanto mediadora pedagógico-cultural, deve valorizar a diversidade linguísticocultural dos estudantes que nela participam, assumindo uma atitude facilitadora das aprendizagens e da construção de conhecimentos (CÉSAR, 2007), incentivando e motivando as aprendizagens, criando um ambiente prazeroso e dinamizador da partilha de saberes e de culturas, estabelecendo pontes entre o aprendente e a aprendizagem. Como sublinha César (2013a, 2013b), uma Escola que assim atua, afirma-se como dialógica e intercultural, realizando transições entre línguas e culturas, contribuindo, deste modo, para o desenvolvimento nos estudantes de mecanismos de inter e intraempowerment que conduzem à participação legítima dos estudantes nos diferentes contextos em que participam: na família, na escola, na sociedade.

Assumindo a necessidade de a Escola se afirmar como espaço e tempo de diversidade cultural e linguística, e no que aos surdos portugueses diz respeito, o Estado português sublinha ser dever da Escola desenvolver um currículo multilingue, ou pelo menos bilingue, encontrando

[...] respostas educativas diferenciadas, de acordo com os níveis de educação e ensino e as características dos estudantes[surdos], nomeadamente através do acesso ao currículo, à participação nas atividades da escola e ao desenvolvimento de ambientes bilingues, promovendo a sua inclusão (ME, 2018, p. 2924). 
No sentido de assegurar aos estudantes surdos equidade no acesso ao currículo, Portugal, dando continuidade a políticas educativas anteriores, reeditando-as no essencial, reforça, deste modo, a necessidade de dotar o país de uma rede nacional de escolas, ditas de referência $(\mathrm{N}=23)$, que respondam adequadamente às necessidades educativas dos estudantes surdos - as escolas de referência para a educação e ensino bilingue de surdos (EREBAS).

Apesar da complexidade política, educativa, geográfica, social e cultural que podem configurar, as EREBAS, pretendem ser

[...] uma resposta educativa especializada com o objetivo de implementar o modelo de educação bilíngue, enquanto garante do acesso ao currículo nacional comum, assegurando, nomeadamente:

a) $O$ desenvolvimento da língua gestual portuguesa (LGP) como primeira língua (L1);

b) O desenvolvimento da língua portuguesa escrita como segunda língua (L2);

c) A criação de espaços de reflexão e formação, incluindo na área da LGP, numa perspetiva de trabalho colaborativo entre os diferentes profissionais, as famílias e a comunidade educativa em geral (ME, 2018).

Organizando-os (segregando-os?) em grupos de estudantes ou turmas, na sua esmagadora maioria exclusivamente constituídos por surdos, estes estudantes são encaminhados para as EREBAS, cujo objetivo principal consistiria numa estratégia nacional de intervenção educativa interdisciplinar e especializada na resposta adequada aos surdos. Assim, as EREBAS, já não seriam uma mera concentração de populações escolares e de recursos humanos, físicos e didático-pedagógicos, mas comunidades identitárias culturais e linguísticas surdas significativas (ALMEIDA et al., 2009), possibilitando o desenvolvimento de construções identitárias múltiplas e dialógicas, assegurando o acesso dos surdos à escolaridade obrigatória, em contexto de educação bilingue, desde a educação pré-escolar ao ensino secundário (MELRO, 2014a).

Para que tais desígnios sejam concretizados, as EREBAS devem dotarse de recursos adequados, como "docentes com formação especializada em educação especial na área da surdez, docentes de LGP, intérpretes de LGP e terapeutas da fala" (ME, 2018, p. 2924), bem como de "equipamentos e materiais específicos que garantem o acesso à informação e ao currículo, 
designadamente equipamentos e materiais de suporte visual às aprendizagens" (ME, 2018, p. 2924)

Apesar das intenções de inclusividade que podem configurar, estas citações alertam-nos, no entanto, para alguns de cariz segregador e excludente ainda presentes neste documento de política educativa. Assim, continua a ocorrer ao que Mesquita, Correia e Rodrigues (2008) já referiam em relação a um passado recente: para além de acentuar a "necessidade de classificar e agrupar alunos por problemáticas, funções e disfunções" (s/p), ao optar por um "sistema de unidades e escolas de referência" ( $/ \mathrm{p})$, poderá estar a contribuir para "desenraizar os alunos das suas comunidades e comprometer a formação da sua rede social de apoio" (s/p).

A estas preocupações, acrescentaríamos as que configuram a emergência, nas escolas que se querem inclusivas, de espaços e tempos educativos segregados e segregadores, como os que subjazem à organização de turmas ou de segmentos letivos constituídos exclusivamente por estudantes surdos, guetizando, separando-os dos outros na maioria dos espaços e tempos que supostamente partilhariam (MELRO, 1999, 2003, 2014a). Note-se que, apesar das EREBAS estarem localizadas em escolas públicas da rede nacional de educação, elas continuam a ser referidas apenas a estudantes, a professores e a outros agentes educativos falantes de LGP. Não estará o previsto neste Decreto-Lei (ME, 2018) a obstaculizar a emergência, na Escola, de espaços e tempos interculturais que favoreçam a realização de transições culturais e linguísticas? Não estaremos, sob a máscara da inclusão, para parafrasearmos Lane (1997), a reeditar a escola de muros, ainda que simbólicos, quando não físicos, segregando, discriminando e excluindo?

A própria distribuição geográfica das EREBAS (MEC, 2009b) mostra alguns dos retrocessos subjacentes às práticas preconizadas neste documento. Concentrando-as maioritariamente no litoral do país (MEC, 2009), ela ilumina como a Escola ainda continua a reproduzir as desigualdades sociais e económicas apresentadas pelas sociedades (PARASKEVA, 2008), reproduzindo ou remetendo para formas subliminares de participação periférica muitos dos surdos portugueses, contrariando princípios de educação inclusivas firmados, como os que constam na Declaração de Salamanca (UNESCO, 1994), que refere ser direito de todos os estudantes frequentarem as escolas da sua vizinhança. Basta pensarmos nos surdos que, por exemplo, vivem no distrito de Bragança, cuja EREBAS mais próxima se encontra a uma distância mínima de $215 \mathrm{Km}$. O 
que significaria, neste caso, para estes estudantes, para as famílias e para as comunidades locais, esta opção? Que impactos individuais e sociais configuraria? E que dizer sobre a opção oposta? Não se estará, sob a máscara da inclusão uma vez mais, a condená-los a optar (sem que verdadeiramente o façam) pelo previsto por este decreto para os surdos que escolham o ensino tido aqui por oralista? Não estará este documento a contrariar ou a contradizer um dos princípios que configuraram a criação das EREBAS: prevenir e reduzir as vivências de isolamento educativo e sociais dos surdos portugueses? Não estaremos, enfim, em presença de um documento que desenvolve, uma vez mais, a exclusão pela inclusão (BAPTISTA, 2008; BARROSO, 2003) - "A escola exclui porque a inclusão deixou de fazer sentido", realça Barroso (2003, p. 27).

Estas preocupações não impedem, porém, que este documento configure alguns avanços. Por exemplo, já não se refere aos surdos como deficientes auditivos, mas como surdos, adotando um paradigma mais valorizador dos surdos e das suas culturas - o paradigma sócio-antropológico (MELRO, 2014a, 2014b). Também já não refere os professores surdos como técnicos ou formadores, mas como docentes, tendo sido criado, recentemente, o respetivo Grupo de Recrutamento (360), referente aos docentes (surdos e/ou ouvintes) de LGP, aprovando as condições de acesso dos docentes desta língua ao concurso externo de seleção e recrutamento do pessoal docente, em condições semelhantes às dos restantes docentes de outras áreas disciplinas (ME, 2018b) - perguntando-nos para quando o reconhecimento oficial na constituição da república portuguesa da LGP como uma das línguas do país, à semelhança do que já acontece com a LP e com a língua mirandesa, denotando as contradições e os paradoxos que iluminam o modo como o país tem atuado perante a comunidade surda portuguesa (MELRO, 2014a).

Também são valorizados os professores de educação especial, bem como outros agentes educativos significativos que atuam em contexto de educação bilingue de surdos, terapeutas da fala ou intérpretes, realçando a necessidade de sobre os surdos lançar um olhar valorizador da diversidade que apresentam, exigindo respostas organizacionais, supervisoras e profissionais colaborativas, dialógicas e interdisciplinares (MELRO, 2014a, 2017a). Sai, ainda, reconhecida, valorizada e celebrada a LGP, assumida já não como instrumento de ensino e de aprendizagem, mas como língua materna, aqui designada como 
"Língua primeira (L1)". Sai, também, valorizada a LP, aqui designada como "Língua segunda (L2)", sem que contudo, ao reduzir a sua aprovação à dimensão escrita, possa deixar de ser interpretada como uma visão amputada quer da própria LP, quer do próprio constructo de bilinguismo, quer ainda dos surdos, deixando antever serem incapazes de apropriar a LP na sua dimensão oral, persistindo uma conceção deficitária dos surdos, bem como uma redutora e homogénea visão da diversidade que os constitui. E que dizer das expressões com que são referidas a LGP e a LP, respetivamente - "Língua primeira (L1)"; "Língua segunda (L2)"? Não denotam elas próprias uma presumível hierarquia linguística e cultural, levando a que se pense ser uma precedente da outra ou mesmo uma superior a outra? Que relações de poder configuram? Que formas de bilinguismo pressupõem? Que formas de diálogo entre línguas e culturas propiciam? Que conhecimento mútuo entre surdos e ouvintes anunciam? Que formas, enfim, de educação, de sociedade e de humanidade poderão assumir?

Estas e outras questões que nos suscitam, levam-nos a considerar, que apesar dos avanços registados, em Portugal, no campo da educação de surdos, passar do dever-ser ao ser continua a não ser uma tarefa simples, nem linear (MELRO, 2010a). Evidenciam, acima de tudo, que, em Portugal, grande parte dos estudantes surdos se vê confrontada no seu dia-a-dia escolar com barreiras linguísticas próprias de quem é ensinado numa outra língua, que não aquela que é a mais adequada às características que apresentam e, por consequência, com barreiras epistemo-gnosiológicas e culturais que pouco parecem favorecer as suas aprendizagens académicas e a sua inclusão nos contextos em que participam, o familiar incluído, porque maioritariamente ouvintes, e cujas interações sociais e pedagógicas, na sua esmagadora maioria, são mediadas em línguas orais como a LP (MELRO, 1999, 2003, 2014a, SOFIATO, 2014). Quando ocorrem ser mediadas numa língua gestual, essa mediação, porque feita por um terceiro, habitualmente por um intérprete de língua gestual, que apesar do importante papel que desempenham, levam-nos a questionar que olhar pedagógico é construído nas interações entre estudantes e professores, bem como entre as famílias e a Escola, ou ainda entre esta e a comunidade surda, como tivemos oportunidade de questionar noutros contextos (MELRO, 2014a, 2017a, 2017b).

A estas preocupações acresce um outro elemento sublinhado pelo Decreto-Lei 54/2018, dizendo respeito ao desenvolvimento de processos de formação especializada que, atempada e adequadamente, propicie aos 
professores e demais agentes educativos, responder consistente e criticamente às características, necessidades e interesses dos estudantes surdos. Contudo, como tivemos oportunidade de discutir, ilumina que, também, neste domínio, a passagem dos princípios às práticas é complexa, reeditando vivências profissionais configuradas por fragilidades, receios, dúvidas, angústias e desesperos de vária ordem (MELRO, 1999, MELRO, 2003, 2014a). Ontem como hoje, a formação especializada dos professores e outros agentes educativos continua a ser lacunar (quando não inexistente), pondo em risco um dos princípios-chave da educação inclusiva de surdos: o desenvolvimento de formação adequada que possibilite aos agentes educativos desenvolver um currículo bilingue/multilingue (MELRO \& CÉSAR, 2005, 2009c, 2012, 2017; MELRO, 2017a, 2017b). Assim, quando, por exemplo, o Decreto-Lei n. 3/2008 (ME, 2008) afirma ser a LP língua não materna (designada neste documento como língua segunda - L2) dos surdos, perguntamos: foi propiciada formação adequada que possibilite aos respetivos professores desenvolver princípios e práticas consonantes com os que subjazem aos processos de ensino e de aprendizagem das línguas nãomaternas para surdos? E que dizer em relação aos docentes que lecionam as diferentes áreas curriculares a estudantes surdos? Foi assegurada formação atempada e consistente, incluindo a apropriação da LGP, que os permita desenvolver um currículo multilingue, ou pelo menos bilingue? Não continuam estes docentes sem apropriar de todo esta língua, ou quando a apropriam, continuam a não se sentir capazes de mediarem as aprendizagens em LGP, dada a pouca fluência que evidenciam, como demonstramos noutros estudos (MELRO \& CÉSAR, 2010a, 2010b; MELRO, 2014a, 2017a, 2017b)?

São muitas as questões! São muitas as dúvidas! Serão muito mais as preocupações e até algumas angústias! Mas a convicção e a esperança de que a mudança é possível, é, com certeza, em nós muito mais forte. É a esta força que alimenta em nós a esperança em que a Escola estabeleça como prioritário da sua praxis o amor pela humanidade, tratando estudantes, professores e demais agentes educativos significativos, com a dignidade que lhes é devida. Esperança numa Escola libertadora e comprometida com a equidade e com a inclusão, que, enquanto tal, e parafraseando Freire, não tem medo de ser amorosa. Esperança numa escola que, como realça este pedagogo, ame as gentes e ame o mundo. Esperança, enfim, e continuando a parafrasear Freire (1999), numa Escola porque ama as pessoas e ama o mundo luta "para que a 
justiça social se implante antes da caridade". Esperança numa escola que, a semelhança do que acontece no conto de Lewis Carrol, Alice no País das Maravilhas, que quando se pergunte sobre a sua identidade saiba reconhecerse na capacidade de se (re)construir na diversidade de rostos ou, como diria Bakhtin (1929/1981) de vozes que a constitui, as dos surdos incluídas, com elas aprendendo e ensinando de que a dor que configura a discriminação, a segregação e a exclusão do seu passado recente, de que a dos surdos é exemplo, não mais pode ser admitida no seu futuro e muito menos no seu presente.

\section{Metodologia}

Relembrando com Freire (1984) que somos seres inacabados, e que essa incompletude é, simultânea e paradoxalmente, a nossa grandeza, porque nos afirma como sujeitos da história que construímos e reconstruímos, o presente estudo surge na continuação do trabalho desenvolvido num projeto mais abrangente - Interacção e Conhecimento (IC)- pluridisciplinar e pluridimensional, cuja duração formal foi de cerca de 12 anos, onde concluímos a nossa especialização em Administração e Gestão Escolar (MELRO, 1999), o nosso Mestrado (MELRO, 2013) e onde foi gerado o nosso Doutoramento que concluímos em 2014 (MELRO, 2014a). O objetivo principal do IC consistia na implementação de práticas colaborativas entre professores, investigadores, bem como entre os estudantes, de modo a aproximar a teoria da prática, o investigador do objeto investigado, estabelecendo diálogo e transições entre diversos contextos: investigativo, educativo, social e cultural (CÉSAR, 2007; HAMIDO \& CÉSAR, 2009).

Tendo como ponto de partida alguns dos resultados retirados da tese de doutoramento que desenvolvemos (MELRO, 2014a), a problemática que aqui nos (pre)ocupa é essencialmente analisar, conhecer, compreender e interpretar o modo como uma comunidade educativa, de uma escola pública de Lisboa, que se constitui como EREBAS, vivencia a inclusão de estudantes surdos adultos ( $\mathrm{N}=11)$, em sistemas formais de educação de adultos, como o ensino recorrente secundário noturno.

Neste artigo, focamos a voz (BAKHTIN, 1929/1981) de uma dessas estudantes - a Madalena, desocultando, através dela, o sentido atribuído às 
representações sociais que os estudantes surdos apresentam sobre a escola, bem como aos modos como esta os inclui.

À exploração destas problemáticas adequa-se uma abordagem interpretativa de cariz etnográfica (DENZIN, 2002), por sublinhar a importância dos contextos e das experiências subjetivas na construção do mundo social, focalizando a realidade de forma complexa e contextualizada (ALVESSON \& SKOLDBERG, 2000.). A investigação constitui-se como um estudo de caso intrínseco (STAKE, 1995; YIN, 1990). Os participantes neste estudo são os 11 estudantes surdos, os pares ouvintes $(\mathrm{N}=6)$, os professores e outros agentes educativos significativos $(\mathrm{N}=47)$, bem como 0 investigador, enquanto observador participante.

Iremos apresentar e discutir episódios que iluminam como a Madalena perceciona e vivencia a sua inclusão neste sistema formal de educação de adultos. Para garantirmos o anonimato, os nomes atribuídos são fictícios. De igual modo, não indicamos o nome da escola onde decorreu o estudo, e outros elementos que possam por em causa o compromisso ético assumido.

Em consonância uma abordagem multidimensional e dialógica (DENZIN, 2002), os instrumentos de recolha de dados foram a entrevista (E); as tarefas de inspiração projetiva (TIP); o questionário (Q); a observação no formato de observador participante (DB); a recolha documental (D).

Focando as respostas dadas pelos participantes às TIP, realçamos a "oportunidade relativamente ilimitada para o exercício e expressão das diferenças individuais" (FREEMAN, 1976, p. 669), que elas propiciam. Realce-se também terem as TIP possibilitado obter respostas diversificadas e flexíveis (ANZIEU, 1981), sublinhando Freeman (1976) que as TIP provocam "respostas que não são corretas nem incorretas, são as próprias interpretações e criações do indivíduo" (p. 69), possibilitando desocultar com profundidade e unicidade o sentido que configura o fenómeno em estudo.

Neste sentido, e focando uma das diversas TIP que apresentámos, solicitámos aos estudantes que escrevessem ou desenhassem, ou ambos, o que é para si a escola, o que se constituiu como uma TIP, no caso a TIP1. Os estudantes levaram cerca de 10 minutos a executar esta tarefa, embora soubessem que não havia tempo limite. A tarefa foi realizada individualmente e por escrito em LP, sendo recolhida pelo investigador, quando terminada. Um dos objetivos desta tarefa era conhecer as representações sociais que estes estudantes construíram sobre a escola e sobre os modos como esta os incluía. 
A opção de solicitarmos aos estes estudantes a realização das TIP e, também do Q em LP escrita foi deliberada e estratégica, tendo-se revelado eficaz para compreender as fragilidades da escola ainda marcada por um certo audismo (LANE, 1997) que, ao mediar hegemonicamente as aprendizagens dos surdos numa língua que não a que é assumida por muitos deles como materna, dificulta a realização dessas aprendizagens, bem como a mobilização de competências e de conhecimentos necessários à sua inclusão escolar e social (MELRO, 2014a, 2014b; MELRO \& CÉSAR, 2009, 2012a, 2102b). Permitiu-nos, ainda, desocultar o sentido da complexidade epistemológica, educativa e ético-política que o bilinguismo em contexto de educação de surdos configura e de que é configurador, denunciando muito dos mitos criados em torno do que significa ser bilingue para os surdos (MELRO, 2014a, 2014b, 2017a, 2017b).

Tal opção não nos impediu, porém, de valorizar a diversidade linguística e cultural dos participantes, (surdos e ouvintes), bem como a criação de um ambiente investigativo que se quer acolhedor dessa diversidade (MELRO, 2014a).

Por termos desenvolvido interações de proximidade com os surdos, e conhecendo as características destes estudantes, a aplicação das TIP e do questionário foi realizada na presença do investigador e com a participação do interprete de LGP, evidenciando-se fundamental para que a resposta às TIP e ao $Q$, por partes destes estudantes, fosse viável e sustentada e possibilitasse recolher informação considerada relevante para a compreensão do fenómeno em estudo, sempre respeitando as opções linguísticas e culturais dos diferentes participantes.

Saliente-se que, referindo "dificuldades no português" (DB, diversas entradas), esta presença foi solicitada pelos estudantes, o que facilitaria, por um lado, ultrapassar barreiras linguísticas e, por outro, sentirem-se mais confortáveis e à-vontade na compreensão do que lhes era pedido. Realce-se que esta opção possibilitou criar laços pessoais e afetivos mais sustentados entre estes estudantes e o investigador, comunicando este, sempre que possível, em LGP, a língua materna da maioria destes participantes surdos. O investigador teve, assim, o cuidado de maximizar duas das principais vantagens da utilização dos questionários: (a) evidenciar como e porquê as diferentes condições individuais e sociais dos participantes iluminam as respostas dadas (GILLHAM, 2000); e (b) realçar, enquanto registo escrito, como o sentido das respostas dadas por indivíduos provenientes de culturas ditas minoritárias, é 
configurado pelas suas competências e desempenhos linguísticos quando confrontados com a língua da cultura dominante que não é a sua língua materna (BAUER \& GASKELL, 2002).

Mais do que as TIP, a realização do questionário revelou-se um processo complexo e moroso, mas muito enriquecedor do ponto de vista investigativo e pessoal. Moroso, porque os estudantes levaram em média 3 a 4 horas para the responder, quando o mesmo questionário ou semelhante, era realizado em média em 15 minutos pelos pares ouvintes, cuja língua materna era a LP. Enriquecedor porque, por um lado, nos permitiu compreender como é, ainda, complexo, para estes estudantes, responderem a um questionário numa língua que, pelas características que apresentam, não lhes podendo ter acesso pleno, não a dominam suficientemente e, por outro lado, porque revelaram o desfasamento que persiste nestes estudantes entre o sentir, o ser e o dizer, quando esta tríade é mediada por uma língua que não a que identificam como materna - a LP (MELRO, 2014a, MELRO \& CÉSAR, 2009).

Gostaríamos, ainda, de realçar que a realização do questionário foi, individual, faseada e sempre na presença do intérprete de LGP, apesar de o investigador falar LGP. Quando os estudantes manifestavam cansaço, interrompíamos o processo e a ele regressávamos numa outra reunião, até à sua conclusão.

Sobre a entrevista gostaríamos de sublinhar que, uma vez que, no presente estudo, alguns dos principais participantes eram surdos, cujas línguas materna assumiam como sendo a LGP ou a LP, entrevistar participantes com as especificidades culturais e linguísticas que os caracterizam exigiu cuidado, flexibilidade, abertura e respeito pela diversidade cultural, linguística e humana. Significa cuidar que as entrevistas sejam mediadas pela língua materna dos participantes (LGP ou LP), efetivando-se a noção epistemológica que configura a relação entre língua, conhecimento e mundo social (BAKHTIN, 1929/1981, VYGOTSKY, 1989).

Apesar de, como já referimos, o investigador falar LGP, recorreu, sempre que necessário e desejado, ao intérprete de LGP para a realização das entrevistas aos estudantes surdos, que manifestaram essa intenção. Deixámos, aliás, ao critério destes participantes, a opção pela presença deste profissional, tendo dois deles optado pela não presença do intérprete. As mesmas foram áudio e vídeo gravadas e, posteriormente, transcritas para LP. 
Recorrendo a uma análise de conteúdo narrativa (CLANDININ \& CONNELLY, 1999) das TIP, do questionário, das entrevistas e da observação, emergiram categorias indutivas sobre as quais urge refletir para analisarmos, compreendermos e interpretarmos a problemática em estudo. Selecionámos para esta apresentação as seguintes categorias: (1) Perceções e consciencialização da Escola e do seu papel na inclusão escolar e social dos estudantes surdos e; (2) Perceção sobre os processos desenvolvidos pela escola como facilitadores da inclusão destes estudantes.

\section{Resultados}

Focando a voz da Madalena, começámos por referir que, depois de frequentar o ensino diurno até ao 10 o ano de escolaridade, numa escola dos arredores de Lisboa, até aos 19 anos, esta estudante surda decidiu, quatro anos mais tarde, voltar à (a esta) escola para "completar o 12ㅇ ano" $(Q$, Madalena).

Surda profunda, assumindo-se como bilingue, a sua trajetória de participação ao longo da vida (TPLV), à semelhança de outros surdos participantes do estudo, é marcada pelo silenciamento a que a voz dos surdos é votada, nomeadamente em sociedades ainda pouco valorizadora das comunidades surdas, como a portuguesa.

Tendo exercido profissões socialmente pouco valorizadas (empregada doméstica, ajudante de cabeleireira, entre outras), esta jovem adulta surda, atualmente desempregada, refere o quanto os surdos ainda são amordaçados (LANE, 1997) pelas sociedades em que participam:

Madalena (M) - É assim, eu quis procurar um emprego só que não consegui. Continuo a procurar um emprego, só que ainda não arranjei. I Pensa que é fácil arranjar trabalho?

M - Não, não. Não é fácil.

I - Porquê?

M - À partida por ser surda. Eu sou capaz de aprender coisas e fazê-las. O problema é que a comunic... as outras pessoas [leia-se, ouvintes] não aceitam comunicar comigo (Madalena, E, p. 1, Retirado de Melro 2014a, p. 270). 
De igual modo, a TPLV em contexto escolar é marcada pelo contínuo e doloroso amordaçamento que muitos dos surdos vivenciaram e continuam a vivenciar numa Escola e sociedade que teima em persistir em formas de atuação que podem ser consideradas audistas (LANE, 1997), levando disempowerment dos surdos, como ilustram os testemunhos da Madalena neste excerto.

Denotando ser a Escola um microcosmos da sociedades, as suas vivencias escolares e sociais têm sido, como ela refere, frequentemente marcadas "por muitas dificuldades" ( $Q$, Madalena), sem que, contudo, a persistência pessoal e coletiva não tenha sobressaído, já que, como ela ilustra na fala acima transcrita, "À partida por ser surda. Eu sou capaz de aprender coisas e fazê-las", reforçada quando relata no questionário, "eu sou surda, mas sou esperta e hei-de conseguir o que quero" ( $Q$, Madalena).

Podendo optar pelo desenho, pelo texto ou por ambos, a Madalena escolheu o texto para expressar as suas representações sociais da Escola. Eis o que a Madalena diz ser a Escola:

Figura 1 - Excerto da resposta da Madalena à TIP1 - Para mim a escola é... a escola para miné

Porque í preciso de aprender todas dischiplina ser mais ixperiencia e compreender...

'f hom de aprender das matcrias navias mas mermo assim que nas gosto de ushodar que tenho pue ser. E peciso de mais experinaía de professional de juhuro.

Fonte: Melro (2010a, s/p)

Das palavras da Madalena podemos depreender, de entre outros aspetos, que, apesar de referir não gostar de estudar algumas componentes do currículo, tem uma representação social positiva da Escola ao afirmar que "é bom de aprender" (TIP, Madalena), ao mesmo tempo que vê na escola um elemento-chave de empowerment como a possibilidade de the proporcionar um futuro melhor, nomeadamente, uma melhor posição profissional- "É preciso de mais experiência de profissional de futuro", realça a Madalena 
A ideia de que, apesar de nem todas as componentes do currículo the agradarem, há que persistir, ou como ela refere "tem de se aprender alguns disciplinas", evidenciando que, apesar das dificuldades sentidas, a Escola poderá ser um elemento-chave de empowerment dos surdos, proporcionando-lhes um futuro pessoal e social mais promissor, porque mais equitativo e inclusivo nos diferentes contextos em que participam, reafirmando esta ideia no questionário ao responder que:

Figura 2 - Excerto da resposta da Madalena ao Q Para mim a escola é importante porque tem ser aprendel de
alorems dusciplina i mais evoluir gle vida entrie mefisrional.

Fonte: Melro (2010a, s/p)

Apesar de a sua TPLV em contexto escolar e profissional ter sido complexa, levando-a, de entre outros, ao abandono precoce da Escola e a exercer profissões pouco valorizadas pela sociedade, é precisamente a esperança de que tudo "não passou de um pesadelo" (DB, várias entradas), e que o futuro será mais prazeroso, que leva a Madalena a justificar o regresso à Escola:

Figura 3 - Excerto da resposta da Madalena ao Q

$\supset$ que me levou a recomeçar a estudar foi dificul dade entre de engrigo i folta de certificalas de escolaridaTrobalho ate berminar al estudo 12:.

Fonte: Melro (2010a, s/p)

Apresentando uma representação social da Escola que podemos interpretar como ainda associada a uma visão tradicional desta instituição, enfatizando ser uma organização centrada em disciplinas que é preciso aprender e "compreender", para obter uma "certificação" e não tanto como um espaço e tempo de vida onde se ensina e aprende e vice versa, a Madalena reforça ser a Escola um elemento-chave de inclusão social. 
Esta é também uma das razões principais da sua motivação e ambição para completar o ensino secundário:

Figura 4 - Excerto da resposta da Madalena ao $Q$

Gostaria de completar o ensino secundário $\nabla$ o ensino universitário $\square$ outro $\triangle$ porque Gorlara de terminar a té 12:ano, pooce foter autro eurso de puofissionais

Fonte: Melro (2010a, s/p)

Internalizando na resposta que apresenta a noção enraizada nem muitos surdos e nas sociedades em que participam, de que não serem os surdos capazes de alcançar níveis de ensino mais valorizados pela sociedade, como os estudos universitários, fruto de paradigmas deficitários que ainda sobre eles permanecem, a esperança que a Escola poderá garantir à Madalena um futuro melhor faz com que que percecione ser possível ter sucesso, afirmando que não vai desistir e estando convicta que vai conseguir completar o 12ㅇaㅇ:

Figura 5 - Excerto da resposta da Madalena ao Q

Penso que vou conseguir $\$ / que não vou conseguir $\square$ porque sim, obrio, tem que rer sem desistir

Fonte: Melro (2010a, s/p)

Elementos como a composição (curta) lexical e sintática, bem como a transposição direta e imediata de muita das estruturas gramaticais da LGP para a LP escrita, sem que entre elas estabeleça transições consistentes, como preconiza o bilinguismo, leva-nos a questionar até que ponto a Escola consegue dar corpo aos ideais de uma educação bilingue de surdos, remetendo os surdos para formas de participação periférica, bem como a que sobre eles recaiam preconceitos e outras formas de atuação pouca valorizadoras da sua diversidade. Como denota o texto (discurso) que apresenta em LP, a Madalena, à semelhança dos pares surdos que assumem a LGP como materna, evidencia o pouco à vontade com que se sente relativamente à língua portuguesa, pelo menos na sua vertente escrita. 
Este e outros episódios, desocultam o sentido que configura os impactos das dificuldades sentidas pela Escola em possibilitar aos surdos o acesso a um currículo multilingue, ou pelo menos, bilingue, consistente e com sentido. As respostas da Madalena quando produzidas em LP escrita evidenciam o quão difícil é mediar as interações sociais e as aprendizagens numa língua à qual não tem acesso pleno, e a quem a Escola não soube desenvolver estratégias de uma melhor apropriação, para que essas dificuldades fossem ultrapassadas ou, pelo menos, mitigadas.

O desconforto que sente ao utilizar a LP, leva-a a adotar estratégias que interpretamos como sendo simultaneamente de sobrevivência linguísticocultural, mas também de exercício de resiliência - optar por escrever frases relativamente curtas e objetivas, evitando correr riscos de errar, com tudo o que simbólica, sub e objetivamente isso poderá significar, perante si e perante o outro.

Estas formas de atuação são assumidas pela Madalena, no decorrer da realização das tarefas em $L P$, ao perguntar se tinha de responder com "muitas palavras" (DB, investigador) revelando um certo receio em, como ela diz, "errar, porque não sei muito de português e escrevo mal e o professor pode não compreender o que respondo" (DB, investigador) - denotando eticidade e cuidado perante o outro.

A este propósito, registe-se que a Madalena apresenta algumas dificuldades em compreender o sentido de quase todas as questões quando apresentadas em LP, recorrendo quase sempre à ajuda do intérprete de LGP para compreender o que se pretendia, como esperado por todos os que procuram conforto em ambientes hostis. Estas dificuldades surgem ou porque a Madalena diz não "conhecer as palavras" (DB, investigador), ou porque, reconhecendo-as, não compreende o sentido das frases apresentadas. É o caso das afirmações "regime presencial" e "regime não presencial" (DB), que diz não saber o que são aquelas palavras e, consequentemente, o que se pretende com elas.

Denotando o quanto a escola falha na afirmação dos surdos como sujeitos participantes legítimos nos contextos em que participam, incluindo o escolar, exigindo à Escola que os mesmos lhe sejam acessíveis, realçamos, que apesar de numa primeira fase evitar recorrer com muita frequência à ajuda da intérprete para elaborar as suas respostas, poderemos considerar que entre o 
que a Madalena diz no texto escrito em LP e o seu discurso em LGP sobre estas mesmas questões há diferenças significativas.

Veja-se a título de exemplo a sua resposta dada à afirmação em LP:

Figura 6 - Excerto da resposta da Madalena ao Q

O que menos gosto na escola é normal que menos gosto na escola é normal $p$ conhecer de
pesseras norras e oumo diferente pue nas
conhecir.

Fonte: Melro (2014a, p. 368)

Pela resposta dada, parece que a Madalena não gosta da Escola porque tem um certo receio em conhecer novas pessoas e que se sente pouco à vontade perante o "outro diferente" ( $Q$, Madalena). Estranhando esta resposta, uma vez que a Madalena nos pareceu ser bastante sociável, o investigador, recorrendo ao intérprete de LGP, perguntou-lhe em LGP se, de facto, ela não gostava de conhecer novas pessoas na escola, ao que ela respondeu em LGP: "adoro conviver e conhecer outras pessoas" (DB, investigador). Esse era um dos aspetos que mais gostava na escola, ao relatar "gosto muito de conhecer pessoas diferentes, e esta escola tem pessoas muito diferentes, com estilos diferentes e isso é muito bom" (DB, investigador).

Este e outros episódios por nós presenciados é revelador dos constrangimentos que estes estudantes sentem e vivenciam no seu dia-a-dia escolar e social, já que estes continuam a ser marcados hegemonicamente por uma língua que não dominam suficientemente, no caso, a LP, para que as suas aprendizagens sejam efetivadas e, sobretudo, para que consigam comunicar, de forma clara, com os professores e com outros interlocutores.

Não será por acaso a Madalena preferir as aulas mediadas por um intérprete de LGP. Também não será por acaso que, à semelhança dos seus pares, uma das disciplinas que menos gosta ser aquela em que, pela sua especificidade científica e didático-pedagógica, e por ser quase exclusivamente mediada em LP, é exigido um elevado domínio desta língua: a Filosofia.

Quando confrontada com as dificuldades linguísticas acima descritas, refletimos a urgência de os surdos verem mediadas as aprendizagens na língua que melhor os permite ter acesso ao currículo. Isso pode ser conseguido se, por exemplo, os apoios educativos propostos pela escola não se limitarem à segregação destes estudantes nas disciplinas ditas teóricas, como Filosofia, a 
disciplina que a Madalena diz não gostar, ou Português, com presença, à época, de um intérprete de LGP em apenas num segmento de 45 minutos semanal, dos 180 minutos previstos para estas disciplinas. Significa, também, ser dever da Escola desenvolver princípios de uma praxis pedagógica visualmente orientada, bem como por outros princípios da educação bilingue de surdos, como os sugeridos por autores como Bagga-Gupta (2004) ou Benvenuto (2004).

Assim, nos quatro segmentos de tempo semanais previstos para estas disciplinas, à altura, não tendo os respetivos professores (todos eles ouvintes) domínio de LGP ou formação especializada no domínio de educação de surdos, a Madalena, tal como a maioria dos pares surdos, não tem acesso à informação de forma semelhante ao que acontece com os pares ouvintes, que muitas vezes assumem como língua materna, ou como L2 em que são fluentes, a língua de instrução, ou seja, a LP. Assim, é importante perguntar: em cenários de educação bilingue de surdos, como conciliar, por um lado, o reconhecimento pela Escola e pelas sociedades que, para alguns surdos, as línguas gestuais são apropriadas como modos privilegiados e muitas vezes únicos de comunicação e de mediação das aprendizagens, com o fazer depender o acesso ao sucesso escolar e social dos indivíduos do acesso às línguas orais, por outro? Como pode a Escola fazer cumprir o previsto nos documentos legais, de que o Decreto-Lei 54/2018 (ME, 2018) é exemplo, que apontam ser um dever da Escola propiciar acesso ao um currículo bilingue e, portanto mediado em LGP e em LP, pelo menos escrita? Como pode a Escola e as sociedades afirmarem-se como inclusivas e interculturais se continuam a insistir em formas de atuação etnocentradas e monoculturais? Como podem indivíduos, como o a Madalena, bem como a maioria dos pares surdos, participar legitimamente nas culturas de que fazem parte se lhes continuam a criar barreiras ao sucesso escolar e social? Como pode a Escola e as sociedades afirmarem-se como equitativas se as formas de atuação que as configuram permanecem no reforço das desigualdades vivenciadas dentro e fora da Escola? Não urge que a Escola adote formas de atuação acolhedoras da diversidade destes estudantes, evitando que os surdos desenvolvam sentimentos como os que a Madalena desenvolveu e connosco partilhou? Não urge dotar a Escola, em particular, os professores, de ferramentas culturais (VYGOTSKY, 1989) que possibilitem mediar as aprendizagens de modo adequado, consistente e com sentido? Não urge, enfim, que a Escola 
desenvolva uma praxis formativa que leve a que os professores se sintam capacitados para desenvolver um currículo bilingue de qualidade com estes estudantes, evitando formas de acolhimento pouco inclusivas, como as relatadas por esta estudante nestes excerto da entrevista que nos concedeu?

\begin{abstract}
Investigador (I) - Como é que acha... Como é que a Madalena acha que os alunos surdos são tratados nesta escola?

Madalena (M) - É assim, são... andam, andam por aí. Portanto, dizem para estudarem em nível de apoio é fraco, na escola.

I - Os alunos surdos são bem aceites nesta escola?

M - É assim, aceita bem e... mas os... [A intérprete teve dificuldade e pediu agora um esclarecimento]. Relativamente aos professores, às vezes têm mais dificuldade em aceitar-nos como surdos. É assim, nós somos inteligentes como as outras pessoas. Somos iguais às outras pessoas. Só que os professores têm de explicar de uma forma que nós percebamos. De uma forma que nós possamos perceber bem. É só isso (Madalena, E, p. 7, Retirado de Melro, 2014a, p. 353).
\end{abstract}

Como evidencia a Madalena, é essencial que os sistemas educativos desenvolvam formas de acolhimento inclusivas dos surdos, fazendo com que se sintam apoiados, reconhecidos e valorizados na sua alteridade, deixando de "andar por aí", entregues à sua sorte. Como salienta na mesma fala, "o apoio é fraco, na escola", urgindo que os professores e outros agentes educativos the respondam adequadamente, ou seja, "têm de explicar de uma forma que nós percebamos", o mesmo é dizer que cumpram o previsto nos ideais da educação bilingue de surdos, como os plasmados na legislação portuguesa (ME, 2018).

Este sentimento é não só corroborado pelos professores que lecionavam a Madalena, como também é por eles vivenciado, reforçando que o desespero de uns é o desespero de outros; que a exclusão de uns é a exclusão de outros; que, enfim, a opressão de uns é a opressão de outros, levando a que a Escola, em vez de se constituir como um espaço e tempo de bem-estar e de conforto, continue a ser, para muitos, um espaço e tempo de desconforto e até de desespero, como ilustram as palavras da Georgina e do Augusto, ambos professores da Madalena:

Investigador (I) - E a pior recordação que tu tens das tuas aulas com os estudantes surdos? 
Georgina - Às vezes o facto de eu não saber língua gestual... às vezes, quando a intérprete não estava, eu queria comunicar ou queria saber o que eles me queriam perguntar, quais eram as dúvidas e temos que recorrer sempre à escrita (Georgina, E, p. 69, retirado de Melro, 2014a, p. 356).

Investigador (I) - Quais são as tuas errrr... as dificuldades que tu sentes a dar aulas a estudantes surdos?

[...]

Augusto (Aug)- Das minhas dificuldades? É pá, cansa. Cansa e às vezes, e às vezes frustra, porque queres que as pessoas, quer dizer, realmente consigam fazer aquilo que se lhes pediu e que consideras como útil para a formação deles eeeee... e não consegues. (...) É isso eeerrrr... o não seres bem tratado, as coisas não 'tarem, não 'tarem, não 'tarem a resultar, o teres queeeee errrrr... o veres que não consegues (Augusto, E, pp. 11-12, adaptado a partir de Melro, 2014a, p.342).

Estes testemunhos iluminam, de forma nítida, os tempos e os contratempos que marcam educação de surdos em Portugal em cenários de educação bilingue. Iluminam o muito do que na Escola e nas sociedades se toma por ignorância, falta de desenvolvimento cognitivo, desinteresse, falta de empenhamento e tantas outras possíveis explicações para o insucesso académico dos estudantes surdos esquecem o essencial: são (quase sempre) eles que têm de fazer o esforço de falar e ser avaliados numa língua que não dominam e à qual, pelas características que apresentam, não podem ter um acesso pleno. Mas, a língua em que muitos deles se sentem confortáveis (a LGP), não foram e nem são ainda apropriadas pela Escola, em particular pelos professores, fazendo com que uns e outros não consigam expressar o que pensam e sentem, com impactos nos processos comunicativos e no sucesso educativo e social. Por isso, se os surdos fossem ensinados e avaliados nas línguas que assume como maternas, ou se lhes fosse propiciado o acesso a currículo multilingue, teriam, provavelmente, desempenhos académicos bem diferentes. O que remete para a questão da equidade de oportunidades, do respeito pela diversidade e dos ambientes de educação formal serem mais, ou menos inclusivos. Remete, igualmente, para a urgência de a Escola desenvolver uma consciência ética e epistemológica que a leve a assumir, nos princípios e nas práticas que apresenta, o compromisso com o empowerment dos surdos, dotando-se dos recursos necessários para que não mais permita 
vivências de opressão, como as vivenciadas pela Madalena e pelos respetivos professores, afirmando -se, enfim, como uma Escola libertadora, porque mais humanista e mais justa, não mais se nutrindo, como diria Freire, do desalento e da miséria (FREIRE, 1987)

\section{Considerações finais}

A educação inclusiva, enquanto ideal educativo, aponta para a construção de um amanhã educacional mais promissor para todos aqueles, que como os surdos, vivenciam um passado e um presente de opressão, expressa em formas de atuação pouco valorizadoras da sua diversidade linguístico-cultural, quando não ao seu silenciamento. No entanto, a voz da Madalena e de outros participantes mostra-nos que, para que esse amanhã aconteça hoje, será necessário derrubar barreiras de várias ordem e natureza, permitindo que os surdos tenham acesso a uma educação que respeite e valorize a sua diversidade e possibilite desenvolver as potencialidades destes estudantes.

Como discutimos, urge que a Escola se afirme como espaço e tempo multicultural e multilingue, respeitando e valorizando as especificidades e necessidades linguísticas dos surdos, criando ambientes educacionais multilingues ou pelo menos bilingues, propícios ao seu desenvolvimento cognitivo, linguístico, emocional, com impactos no seu empowerment individual e coletivo. Por isso, como a voz da Madalena e de outros participantes evidenciou, urge ultrapassar obstáculos epistemológicos, educacionais e culturais que dificultam que os surdos realizem, como diria Freire $(1984,1999)$, de forma crítica e cidadã, a (sua) leitura do mundo, com ele interagindo de modo legítimo e prazeroso, fazendo cumprir um dos principais desígnios da Escola e anunciado por Paulo Freire: a adotar uma pedagogia "que faça da opressão e de suas causas objeto da reflexão dos oprimidos, de que resultará o seu engajamento necessário na luta por sua libertação, em que esta pedagogia se fará e refará" (FREIRE, 1987, p. 17)!

\section{Referências}

ALLAN, J., \& SLEE, R. Doing inclusive education research. Rotterdam: Sense Publishers, 2008. 
ALMEIDA, D., CABRAL, E., FILIPE, I., \& MORGADO, M. Educação bilingue de alunos surdos: Manual de apoio à prática. Lisboa: Ministério da Educação (ME): Direção-Geral de Inovação e de Desenvolvimento Curricular (DGIDC), 2009.

ALVESSON, M., \& SKOLDBERG, K. Reflexive methodology: New vistas for qualitative research. London: Sage, 2000.

ANZIEU, D. Os métodos projectivos. RJ: Editora Campus, 1981.

APEL, K-O. Le logos propre au langage humain. Cahors: Ed. de l'Eclat, 1994.

BAGGA-GUPTA, S. Literacies and deaf education. Stockholm: Myndigheten för Skolutvec-kling, 2004.

BAKHTIN, M. The dialogical imagination (M. Holquist, Ed.) (M. Holquist, \& C. Emerson, Trans.). Austin, TX: University of Texas Press, 1981. [Original publicado em Russo, em 1929]

BAPTISTA, A. J. Os surdos na escola. A exclusão pela inclusão. Vila Nova de Gaia: Fundação Manuel Leão, 2008.

BARROSO, J. Políticas educativas e organização escolar. Lisboa: Universidade Aberta (UA), 2005.

BENVENUTO, A. What is Deafness? (Or, what do we mean when we talk about the "Deaf"). In: Reach Canada (Eds.), Canadian conference on mental health and deafness: Working together for a shared future: Conference proceedings. Ottawa: Reach Canada, 2004. Disponível em:

http://www.reach.ca/shared_future/eng/table.htm. Acesso em: 12 jun. 2020.

CÉSAR, M. Dialogical identities in students from cultural minorities or students categorised as presenting SEN: How do they shape learning, namely in mathematics?. In ScTIG Group (Eds.). 2nd socio-cultural theory in educational research \& practice conference proceedings. Manchester: University of 
Manchester, 2007. Disponível em:

www.Ita.education.manchester.ac.uk/ScTIG/index.htm. Acesso em: 23 jun. 2020.

CÉSAR, M. Educação especial: Pequenos passos, alguns retrocessos e muito caminho para andar. Interacções, v. 8, n. 21, p. 68-94, 2012. Disponível em: http://revistas.rcaap.pt/interaccoes/article/view/1523. Acesso em: 2 nov. 2016.

CÉSAR, M. Collaborative work, dialogical self and inter-/intra-empowerment mechanisms: (Re)constructing life trajectories of participation. In M. B. Ligorio, \& M. César (Orgs.), Interplays between dialogical learning and dialogical self. Charlotte, NC: Information Age Publishing (IAP), 2013a, p. 151-192.

CÉSAR, M. Cultural diversity and regulatory dynamics of participation between schools and families. In P. Marsico, K. Komatzu, \& A. lannaccone (Orgs.), Crossing boundaries: Intercontextual dynamics between family and school. Charlotte, NC: IAP, 2013b, p. 35-81.

CÉSAR, M., \& AINSCOW, M. (Eds.). European Journal of Psychology of Education, v. XXI, n. 3, 2006.

CLANDININ, D. J., \& CONNELLY, F. M. Personal experience methods. In N. K. Denzin, \& Y. S. Lincoln (Orgs.), Collecting and interpreting qualitative materials. Thousand Oaks, CA: Sage Publications, 1999, p. 150-178.

DELORS, J., MUFTI, I., AMAGI, I., CARNEIRO, R., CHUNG, F., GEREMEK, B., GORHAM, W., KORNHAUSER, A., MANLEY, M., QUERO, M., SAVANÉ, M.-A., SINGH, K., STAVENHAGEN, R., SUHR, M., \& NANZHAO, Z. Educação: Um tesouro a descobrir. Porto: Edições Asa, 2003.

DENZIN, N. The interpretative process. In A. Haberman, \& M. Mieles (Eds.), The qualitative researchers companion. Thousand Oaks, CA: Sage Publications, 2002, p. 349-366. 
FORLIN, C. Teacher education reform for enhancing teachers' preparedness for inclusion. International Journal of Inclusive Education. 14(7), p. 649-653, 2010.

FREEMAN, F. S. Teoria e prática dos testes psicológicos. Lisboa: Fundação Calouste Gulbenkian, 1976.

FREIRE, P. Educação como prática de liberdade: A sociedade brasileira em transição. R J: Editora Paz e Terra, S.A., 1967/2000. Disponível em: http://www.gestaoescolar.diaadia.pr.gov.br/arquivos/File/otp/livros/ educacao_pr atica_liberdade.pdf. Acesso em: 6 jun. 2020.

FREIRE, P. Pedagogia do oprimido, 17. ed., RJ: Paz e Terra, 1987.

FREIRE, P. Pedagogia da esperança: Um reencontro com a pedagogia do oprimido,17. ed., SP: Editora Paz e Terra, 1999.

GILLHAM, B. Developing a questionnaire. London/New York, UK/NY: Continuum, 2000.

HAMIDO, G., \& CÉSAR, M. Surviving within complexity: A meta-systemic approach to re-search on social interactions in formal educational scenarios. In K. Kumpulainen, C. Hmelo-Silver, \& M. César (Orgs.), Investigating classroom interactions: Methodologies in action. Rotterdam: Sense Publishers, 2009, p. 229-262.

INE (2019). Taxa de abandono precoce de educação e formação. Disponível em:https://www.ine.pt/xportal/xmain?

xpid=INE\&xpgid=ine_indicadores\&contecto=pi\&indOcorrCod=0006268\&selTab =tab0\&xlang=pt. Acesso em: 12 jul. 2020.

LANE, H. A máscara da benevolência: A comunidade surda amordaçada ( $R$. Leite, Trad.). Almada: Instituto Piaget, 1997. [Original publicado em inglês, em 1992] 
LAVE, J., \& WENGER, E. Situated learning: Legitimate peripheral participation. Cambridge, UK: Cambridge University Press, 1991.

MELRO, J. Escola inclusiva: Uma análise reflexiva feita em torno de um projecto de inclusão de alunos com necessidades educativas especiais no ensino regular. (Estudo exploratório, apresentado na Universidade de Lisboa, documento policopiado). DEFCUL, Lisboa, 1999.

MELRO, J. Escola Inclusiva: Uma história de amor (nem sempre) bem contada. 2003. Dissertação (Mestrado em Educação), documento policopiado. Lisboa: DEFCUL, 2003.

MELRO, J. Do gesto à voz. Um estudo de caso sobre a inclusão de estudantes Surdos no ensino secundário recorrente nocturno. 2014. Tese. (Doutorado em Educação)- Instituto de Educação da Universidade de Lisboa, Lisboa, 2014a.

MELRO, J. Língua, participação e poder. Educação Inclusiva, 5(1), II-III. [Dossier temático: A aprendizagem da Língua Portuguesa por surdos, editor Joaquim Melro], s/p, 2014b.

MELRO, J. Formação de professores e educação intercultural de surdos em Portugal: o caso do ciclo de conferências do gesto à voz: educação de surdos e inclusão. Revista Espaço, 47. ed., jan./jun., p. 21-41, 2017a. Disponível em [http://www.ines.gov.br/seer/index.php/revista-espaco/article/view/353/ pdf\#]. Acesso em 21 jun 2020

MELRO, J. Educação inclusiva de surdos: o tempo dos professores, O Tempo dos Professores. L. G. Correia, R. C. Leão \& S. Poças (Orgs.), Porto: CIIE - Centro de Investigação e intervenção Educativas (CIIE) Faculdade de Psicologia e de Ciências da Educação da Universidade do Porto (FPCEUP), 2017b, pp. 11111133. Disponível em:

https://www.fpce.up.pt/otempodosprofessores/O_Tempo_dos_Professores_ monografia_LGC_RL_SP_CIIE_2017.pdf. Acesso em: jul. 122020. 
MELRO, J. Escola inclusiva: Aquém ou além do pleonasmo (educativo)?. In B. Silva, \& L. Almeida (Eds.), Actas do VIII congresso galaico de psicopedagogia (pp. 1851-1876). Braga: Universidade do Minho, 2005. [CdRom]

MELRO, J.; CÉSAR, M. Educação inclusiva: Do ser ao agir e do dizer ao sentir. In A. Estrela, L. Marmoz, R. Canário, J. Ferreira, B. Cabrito, N. Alves, P. Figueiredo (Orgs.), Actas do XVI Colóquio da AFIRSE. Tutoria e mediação em educação: Novos desafios à investigação educacional. Lisboa: Secção Portuguesa da AFIRSE, 2009, s/p [CdRom]

MELRO, J.; CÉSAR, M. Desafios profissionais da educação inclusiva: A voz dos professores. In A. Estrela, L. Marmoz, R. Canário, J. Ferreira, B. Cabrito, N. Alves, et al. (Eds.), Actas do XVII Colóquio AFIRSE. A escola e o mundo do trabalho. Lisboa: Secção Portuguesa da AFIRSE, , s/p, 2010a. [CdRom]

MELRO, J.; CÉSAR, M. Educação inclusiva: Desafios à profissionalidade docente e às aprendizagens dos alunos Surdos. Educação inclusiva, 1(2), pp.10-17, 2010b.

MELRO, J.; CÉSAR, M. M. Abraçando e efectivando a inclusividade: O exemplo da inclusão de alunos Surdos no ensino regular. In I. Sanches, M. Costa, A. Mota, \& Á. Santos (Orgs.), Para uma educação inclusiva: Dos conceitos às práticas. Lisboa: Edições Universitárias Lusófonas, vol. I, pp. 255-272, 2012a.

MELRO, J. \& CÉSAR, M. Educação inclusiva e equidade: Um estudo de caso com adultos surdos do ensino secundário recorrente nocturno. In L. Lima-Rodrigues \& D. Rodrigues (Orgs.), Atas do III Congresso Internacional Educação Inclusiva e Equidade Almada: Pro-Inclusão: Associação Nacional de Docentes de Educação Especial (Pin-ANDEE), Parte II, p. 550-567, 2013.

MELRO, J. \& CÉSAR, M. Inclusão de estudantes adultos surdos no ensino recorrente nocturno: Uma (segunda) oportunidade para quem?!. Interacções, 10(33), p.128-162, 2014. Disponível em:

http://revistas.rcaap.pt/interaccoes/article/viewFile/6733/5028. Acesso em: 4 jun. 2020. 
MELRO, J. \& CÉSAR, M. Inclusão e equidade na educação de surdos adultos. Journal of Re-search in Special Educational Needs, 16(v1), pp. 614-618, 2016. Disponível em: http://onlinelibrary.wiley.com/doi/10.1111/jrs3.2016.16.issueS1/issuetoc. Acesso em: 2 jun. 2020.

MELRO, J. \& CÉSAR, M. Educação de surdos adultos em Portugal: A(s) voz(es) dos professores. Deaf adult education in Portugal: The teacher's voice(s). XIV Congreso Psicopedagogía. Área 11: Necesidades Educativas Especiales, Vol. Extr., 11(2017), pp. 290-301, 2017. Disponível em: https://doi.org/10.17979/reipe.2017.0.11.3039. Acesso em: 26 maio 2020.

MINISTÉRIO DA EDUCAÇÃO (ME). Decreto-Lei n.o 3/08, de 7 de Janeiro. Diário da República - I Série, n. 4. Lisboa: Imprensa Nacional Casa da Moeda (INCM), 2008.

MINISTÉRIO DA EDUCAÇÃO E CULTURA (MEC) Mapa da rede de escolas de referência existentes no país, 2009. Disponível em: http://area.dgidc.minedu.pt/mapa_especial/mapa_de_portugalCegosSurdos.h tml. Acesso em: 5 jun. 2020.

MORIN, E. Os sete saberes para a educação do futuro. Lisboa: Instituto Piaget, 2002.

ONU. Convention on the rights of persons with disabilities, 2007. Disponível em: http://www.un.org/disabilities/default.asp?navid=14\&pid=150. Acesso em: 3 jul. 2020.

PARASKEVA, J. Educação e poder. Abordagens críticas pós-estruturais, v. 1. Mangualde: Edições Pedagogia Ltda., 2008.

PORDATA. Taxa de abandono precoce de educação e formação, 2008. Disponível em:

https://www.pordata.pt/Portugal/Taxa+de+abandono+precoce+de+educa \%c3\%a7\%c3\%a3o+e+forma\%c3\%a7\%c3\%a3o+total+e+por+sexo-433-4678. Acesso em: 5 jun. 2020. 
SOFIATO, C. G. Experiência educacional inclusiva e surdez: conquistas e desafios. In: R. Ribeiro. (Org.). Educação Especial: olhar o presente para pensar o futuro. São Paulo, SP: Quinta ventura Livros \& UNESP, 2014, v. 1, p. 149-171.

STAKE, R. E. The art of case study research. Thousand Oaks: Sage Publications, 1995.

UNESCO. The Salamanca statement and framework for action on special needs education. Salamanca: UNESCO \& Ministry of Education and Science, 1994.

UNESCO. Education for all by 2015: Will we make it?, 2015. Disponível em: http://unesdoc.unesco.org/images/0015/001547/154743e.pdf. Acesso em: 3 jul. 2020.

VERGNAUD, G. Représentation et activité: Deux concepts étroitement associés. Recherches en Education, v. 4, p. 9-22, 2007.

VYGOTSKY, L. S. Pensamento e linguagem. SP: Martins Fontes, 1989.

YIN, R. Case study research: Design and methods. Newbury Park, CA: Sage Publications, 1990. 